\title{
PECULIARITIES OF DOPING OF ZnO:Mn NANOCRYSTALS DURING THEIR SYNTHESIS BY THE AEROSOL PYROLYSIS METHOD
}

\author{
O.V. Kovalenko, V.Yu. Vorovsky, O.V. Khmelenko, Ye.G. Plakhtii \\ Oles Honchar Dnipro National University, Dnipro, Ukraine \\ e-mail:kovalenko.dnu@gmail.com
}

\begin{abstract}
Samples of ZnO:Mn nanocrystals with Mn concentrations of 2 and 4 at.\% were synthesized by ultrasonic aerosol pyrolysis. The synthesis was carried out at $550^{\circ} \mathrm{C}$ using aqueous solutions of zinc and manganese nitrates. The samples obtained were subjected to heat treatment at $550^{\circ} \mathrm{C}$ and $850^{\circ} \mathrm{C}$ in air for 1 hour. The study of the samples by XRD and EPR methods shows that during the synthesis the process of doping $\mathrm{ZnO}$ nanocrystals with manganese occurs only partially, on the surface, in the near-surface layer. Residues of the Mn impurity are located on the surface of nanocrystals and appear during annealing at $550{ }^{\circ} \mathrm{C}$ in the form of manganese oxides $\left(\mathrm{Mn}_{2} \mathrm{O}_{3}\right)$. During heat treatment at $8500^{\circ} \mathrm{C}$, decomposition of $\mathrm{Mn}_{2} \mathrm{O}_{3}$ and bulk doping of $\mathrm{ZnO}$ :Mn nanocrystals occur.
\end{abstract}

Keywords: zinc oxide, manganese, ultrasonic aerosol pyrolysis, nanocrystal, heat treatment.

Received 19.10.2020; Received in revised form 23.11.2020; Accepted 02.12.2020

\section{Introduction}

In recent years, dilute magnetic semiconductors (DMS) have attracted special attention of researchers in connection with the possibility of their use in spintronics [1]. A large number of works have been devoted to the study of DMS obtained by doping $\mathrm{ZnO}$ with transition metals. This is due to the fact that in [2] the ferromagnetic properties of Mn-doped $\mathrm{ZnO}$ nanocrystals $(\mathrm{NC})$ at room temperatures were predicted theoretically. Experimentally this prediction was proved in [3]. The results were obtained [4], which showed the existence of ferromagnetic properties in $\mathrm{ZnO}: \mathrm{Mn} \mathrm{NC}$ samples synthesized by aerosol spray pyrolysis (ASP) at room temperatures. These properties disappeared after annealing the samples in air at $T=800^{\circ} \mathrm{C}$ and depended on the technological conditions of synthesis.

The ASP method compares favorably with all other methods for the preparation of DMS in that it is simple, it allows one to obtain nanomaterials in the form of both powder and films. This method is based on the thermal decomposition of aerosol droplets of the initial solution as they pass through the thermal zone. A feature of the synthesis of NC by the ASP method is that $\mathrm{NC}$ are formed within a short period of time in the volume of a microdroplet, under nonequilibrium conditions. This leads to the appearance of a large number of defects in $\mathrm{NC}$, which significantly affect the physical properties of the synthesized product. In this case, it is important to study the possibility of doping NC with impurities in a short time, under nonequilibrium crystallization conditions during synthesis. The paper presents the results of studying the doping process of $\mathrm{ZnO}: \mathrm{Mn} \mathrm{NC}$ obtained by the ASP method before and after annealing.

\section{Materials and methods}

Samples of $\mathrm{ZnO}: \mathrm{Mn} \mathrm{NC}$ were obtained by the ASP method with Mn concentrations of 2 and 4 at.\%. Zinc nitrates $\left(\mathrm{Zn}\left(\mathrm{NO}_{3}\right)_{2} \cdot 6 \mathrm{H}_{2} \mathrm{O}\right)$ and manganese nitrates $\mathrm{Mn}\left(\mathrm{NO}_{3}\right)_{2} \cdot 6 \mathrm{H}_{2} \mathrm{O}$ were used as precursors in the synthesis. A prepared aqueous $10 \%$ solution of zinc nitrate with the required amount of manganese nitrate was sprayed onto aerosol droplets $d=1-2 \mu \mathrm{m}$ in size. These drops were transported with the help of a carrier gas (air) through the reaction zone of the furnace heated to a temperature of $550^{\circ} \mathrm{C}$ where, for a limited time $(7 \div 10 \mathrm{~s})$, the processes of droplet drying and synthesis of $\mathrm{ZnO}: \mathrm{Mn} \mathrm{NC}$. The synthesized product in the form of spherical granules was accumulated on the filter at a temperature of $250^{\circ} \mathrm{C}$ [5]. Heat treatment of the obtained samples was carried out in air at $T_{1}=550^{\circ} \mathrm{C}$ and $T_{2}=850^{\circ} \mathrm{C}$ for one hour. The study of the crystal structure and phase composition of the samples was carried out 
by the method of X-ray diffraction analysis (XRD) on a DRON-2 diffractometer using Co $\mathrm{K}_{\alpha}$ radiation $(\lambda=0.17902 \mathrm{~nm})$. The EPR study of the samples was carried out on a RADIOPAN SE/X 2543 radio spectrometer. The magnetic properties of the samples were studied by vibration magnetometry.
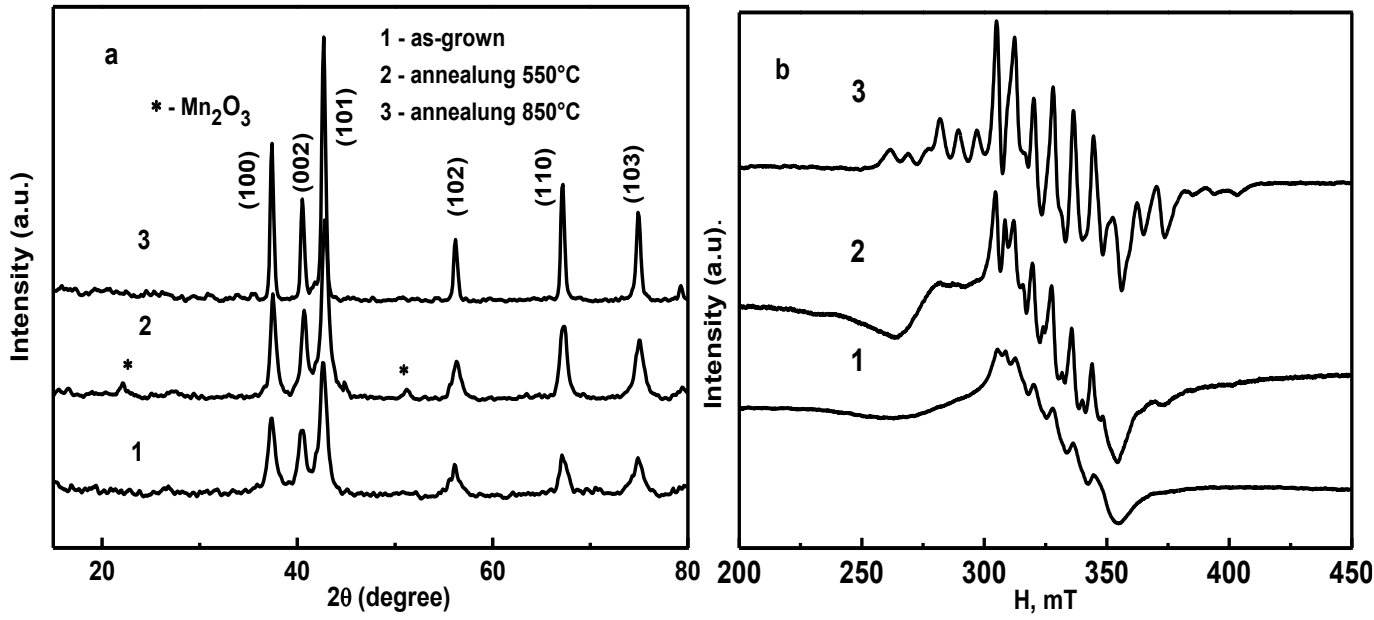

Fig. 1. X-ray diffraction patterns of a ZnO:Mn NC sample (4 at\%) (a) and its EPR spectra (b): 1 - before annealing, 2 - after annealing at $T_{1}=550^{\circ} \mathrm{C}$,

3 - after annealing at $\mathrm{T}_{2}=850^{\circ} \mathrm{C}$ in air for one hour. Symbol * indicates $\mathrm{Mn}_{2} \mathrm{O}_{3}$ phase.

The average size of $\mathrm{NC} \mathrm{ZnO}: \mathrm{Mn}$ was calculated by the Scherer formula [6] with taking into account the expansion of the reflexes of radiographs:

$$
D=\frac{k \lambda}{\beta \cos \theta}
$$

where $k=0.9$ (const) is a dimensionless shape factor varies with the actual shape of the crystallite, $\lambda$ is the X-ray wavelength $(\lambda=0.17902 \mathrm{~nm}), \beta$ is the line broadening at half the maximum intensity (FWHM), after subtracting the instrumental line broadening, in radians, $\theta$ is the Bragg angle.

For the hexagonal structure of $\mathrm{ZnO}$, the interplanar spacing $\mathrm{d}_{(\mathrm{hkl})}$ is related to the lattice constants $a, c$ and Miller indices as follows:

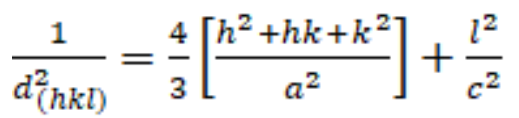

The values of the lattice parameters $a$ and $c$ for the samples are determined by the equations:

$$
\begin{gathered}
a=\frac{\lambda}{2 \sin \theta} \sqrt{\frac{4}{3}\left(h^{2}+h k+\frac{l^{2}}{(c / a)^{2}}\right)}, \\
c=\frac{\lambda}{2 \sin \theta} \sqrt{\frac{4}{3(a / c)^{2}}\left(h^{2}+h k+l^{2}\right)} .
\end{gathered}
$$

The unit cell volume for the hexagonal system is calculated using the equation:

$$
V=\frac{\sqrt{3} a^{2} c}{2}=0.866 a^{2} c \text {. }
$$

The calculation results are shown in Table 1. Their analysis shows that the values of the crystal lattice parameters $(a, c)$ and the unit cell volume $(V)$ of the samples before annealing and after annealing at $T_{1}=550^{\circ} \mathrm{C}$ practically do not differ from such values of 
the non-doped $\mathrm{NC} \mathrm{ZnO}$ [5]. This is a consequence of the fact that during the synthesis of $\mathrm{ZnO}: \mathrm{Mn} \mathrm{NC}$ under nonequilibrium conditions, Mn doping practically does not occur. An increase in these parameters after annealing the sample at a high temperature $T_{2}=850^{\circ} \mathrm{C}$ indicates that under these conditions the process of bulk doping of $\mathrm{ZnO} \mathrm{NC}$ occurs by replacing zinc ions $\mathrm{Zn}^{2+}$ with manganese ions $\mathrm{Mn}^{2+}$, which have a larger ionic radius (in the wurtzite structure, the ionic radius $\mathrm{Mn}^{2+}$ is $0.83 \AA$, and $\mathrm{Zn}^{2+}$ is $0.74 \AA$ ). In the synthesized samples, an increase in the Mn concentration leads to a decrease in the average size of $\mathrm{NC}$, because impurity atoms retard the growth of $\mathrm{NC}$ in the direction of the surface on which they are located.

Table 1

Crystal lattice parameters $(a, c)$, average crystal size $(d)$, unit cell volume $(V)$ of $\mathrm{NC} \mathrm{ZnO}$ and $\mathrm{ZnO}$ :Mn

\begin{tabular}{|l|l|l|l|l|l|l|l|l|}
\hline \multirow{2}{*}{\multicolumn{1}{|c|}{ Sample }} & \multicolumn{5}{|c|}{ Mn concentration 2.0 at\% } & \multicolumn{3}{c|}{ Mn concentration 4.0 at\% } \\
\cline { 2 - 9 } & $\begin{array}{l}d, \\
\mathrm{~nm}\end{array}$ & $a, \AA$ & $c, \AA$ & $V, \AA^{3}$ & $d, \mathrm{~nm}$ & $a, \AA$ & $c, \AA$ & $V, \AA^{3}$ \\
\hline ZnO, pyrolysis [5] & \multicolumn{6}{|c|}{$D=56 \mathrm{~nm}, a=3.2415 \AA, c=5.1946 \AA, V=47.12 \AA^{3}$} \\
\hline Synthesized & 35.8 & 3.2352 & 5.1951 & 47.08 & 33.6 & 3.2395 & 5.1873 & 47.14 \\
\hline Annealing at $550^{\circ} \mathrm{C}$ & 38.6 & 3.2389 & 5.2014 & 47.19 & 34.9 & 3.2396 & 5.1876 & 47.15 \\
\hline Annealing at $850^{\circ} \mathrm{C}$ & 93.7 & 3.2525 & 5.2105 & 47.73 & 104.2 & 3.2403 & 5.1917 & 47.21 \\
\hline
\end{tabular}

An EPR study of the ZnO:Mn NC sample with a manganese concentration of 4 at\% (Fig. 1b) also confirms the necessity of annealing the sample at a high temperature for doping it with Mn. The amplitude of the lines of the hyperfine structure (HFS) of the EPR spectrum after annealing at a temperature of $T_{2}=850^{\circ} \mathrm{C}$ significantly increases, which is associated with a significant increase in the concentration of $\mathrm{Mn}^{2+}$ ions in the bulk of the $\mathrm{ZnO}$ NC. These studies also show that the EPR spectrum after annealing the sample at $T_{1}$ $=550^{\circ} \mathrm{C}$ has additional peaks (Fig. $1 \mathrm{~b}$ ). It is assumed that the presence of these peaks is due to the presence of $\mathrm{Mn}^{2+}$ ions in the sample in a different local environment. It is possible that this is facilitated by the formation of an impurity phase $\mathrm{Mn}_{2} \mathrm{O}_{3}$ (Fig. 1a). In addition, it is found that the amplitude of the HFS of the EPR spectrum after annealing the sample at $T_{1}=550^{\circ} \mathrm{C}$ increases. It is most likely that, during the annealing of the sample, one part of the Mn impurity, which was in the amorphous state, diffuses into the surface layer of $\mathrm{ZnO} \mathrm{NC}$, increasing the concentration of $\mathrm{Mn}^{2+}$ ions, while the other part of this impurity crystallizes, forming the $\mathrm{Mn}_{2} \mathrm{O}_{3}$ phase.

The analysis of the EPR spectra of the ZnO:Mn NC sample with a Mn concentration of 4 at\% (Fig. 2) shows that the maxima of the main lines of the HFS of the sample before (1) annealing and after (2) annealing coincide (group of lines SI). The maxima of the additional HFS (group of SII lines) in the sample after annealing at a temperature of $T_{1}=550^{\circ} \mathrm{C}$ (2) are shifted relative to the maxima of the main HFS by the value of $\Delta H=3.9 \mathrm{mT}$. The width values of the group of lines SI and SII for all EPR spectra are the same and equal to $\Delta H_{1}=\Delta H_{2}=39.5 \mathrm{mT}$. The calculation of the average value of the hyperfine structure constant of the EPR spectra shows that they are approximately the same and equal to $A_{1}=A_{2}=A_{3} \sim 7.9 \mathrm{mT}$. This value is close to the value $A=7.6 \mathrm{mT}$, which corresponds to the tetrahedral environment of the $\mathrm{Mn}^{2+}$ ion in the $\mathrm{ZnO} \mathrm{NC}$. It is also found that the $g$-factor of the EPR spectra (1), (2), and (3) of the sample does not change, it is equal to $g_{1}=g_{2}=g_{3}=2.019$. For the EPR spectrum of additional peks, to which the group of SII lines corresponds, the $g$-factor has the value $g_{\text {II }}=1.998$. This value of the $g$-factor may indicate that after annealing the sample at a temperature of $T_{1}=550^{\circ} \mathrm{C}$, the $\mathrm{Mn}^{2+}$ ions are in a deformed environment on the surface of the $\mathrm{ZnO}$ NC. These conclusions 
coincide with the results of work [7]. In this paper, the authors showed that after annealing $\mathrm{ZnO}: \mathrm{Mn} \mathrm{NC}$ at a temperature $T \sim 500^{\circ} \mathrm{C}$, an additional group of SII lines appears in their EPR spectrum, which is caused by $\mathrm{Mn}^{2+}$ ions located in a thin shell of zinc hydroxide $\mathrm{Zn}(\mathrm{OH})_{2}$, covering surface of $\mathrm{NC} \mathrm{ZnO}$.

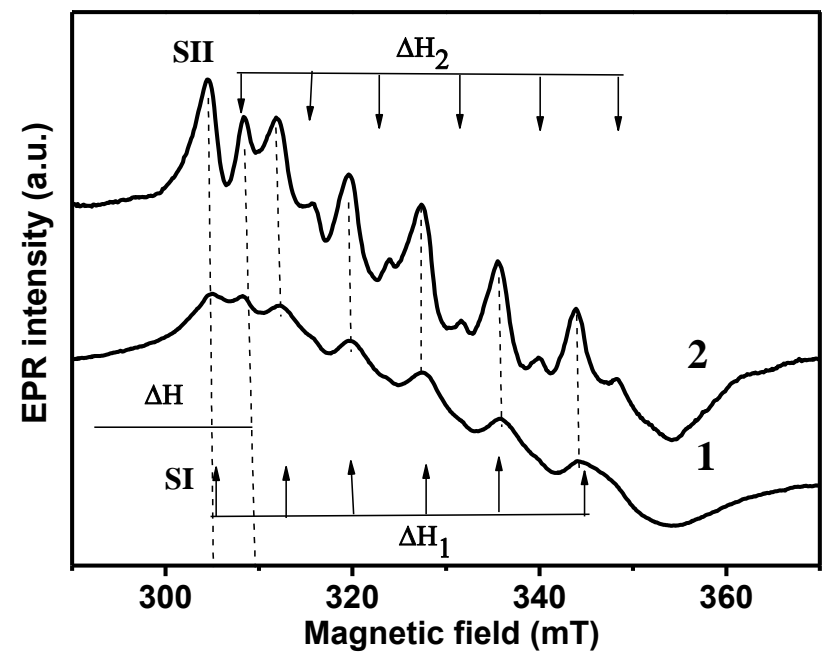

Fig. 2. EPR spectra of a $\mathrm{ZnO}: \mathrm{Mn}$ NC sample with a manganese concentration of 4 at \%: 1 - before annealing, 2 - after annealing at $T=550{ }^{\circ} \mathrm{C}$.

\section{Conclusion}

It is shown that the main feature of doping $\mathrm{ZnO} \mathrm{NC}$ with manganese during their synthesis by ultrasonic aerosol pyrolysis is the inhomogeneous arrangement of the $\mathrm{Mn}$ impurity in the volume of the NC. Under short-term, nonequilibrium conditions of NC formation, the Mn impurity does not spread over the entire volume of the $\mathrm{ZnO} \mathrm{NC}$, but is concentrated in its near-surface layer. Only annealing at a temperature of $T=850^{\circ} \mathrm{C}$ for 1 hour in air leads to the diffusion of Mn impurities into the bulk of the NC.

The obtained results are of practical importance. They can be used to optimize the modes of DMS synthesis by ultrasonic aerosol pyrolysis.

\section{References}

1. Pogorily, A.M. Spintronics. Basic Phenomena. Trends of development / A.M. Pogorily, S.M. Ryabchenko, A.I. Tovstolytkin // Ukr. J. Phys. Reviews. - 2010. - Vol. 6. - P. 37-97.

2. Dietl, T.Zener Model Description of Ferromagnetism in Zinc-Blende Magnetic Semiconductors / T. Dietl, H. Ohno, F. Matsukura, J. Cibert, D. Ferrand// J. Science. - 2000. - Vol. 287. - P. 1019-1022.

3. Sharma, P. Ferromagnetism above room temperature in bulk and transparent thin films of Mn-doped ZnO / P. Sharma, A. Gupta, K.V. Rao, F.J. Owens, R. Sharma, R. Ahuja, J.M. Osorio Guillen, B. Johansson, and G.A. Gehring_/ Nature Mater. - 2000. - Vol. 2. - P. 673-677.

4. Vorovsky, V.Y. Preparation of zincoxide nanopowders doped with manganese which have ferromagnetic properties at room temperature / V.Y. Vorovsky, A.V. Kovalenko, A.I. Kushneryov, O.V. Khmelenko // J. Functional Materials. - 2018. - Vol. 25, No. 1. - P. 61-66.

5. Bulaniy, M.F. Synthesis of Nanopowders $\mathrm{ZnO}$ and $\mathrm{ZnO}$ :Mn by Ultrasonic Sprey Pyrolysis / M.F. Bulaniy, V.Yu. Vorovsky, A.V. Kovalenko, O.V. Khmelenko // J. NanoElectron. Phys. - 2016. - Vol. 8, No. 2. - P. 02043-02048.

6. Patterson, A.L. The Scherrer Formula for X-Ray Particle Size Determination / A.L. Patterson // J. Phys. Rev. - 1939. - Vol. 56. - P. 978-982.

7. Zhou, H. Magnetic resonance investigation of $\mathrm{Mn}^{2+}$ in $\mathrm{ZnO}$ nanocrystals / $\mathrm{H}$. Zhou, DM. Hofmann, A. Hofstaetter, B.K. Meyer // J. Appl. Phys. - 2003. - Vol. 94 - P. 1965-1968. 